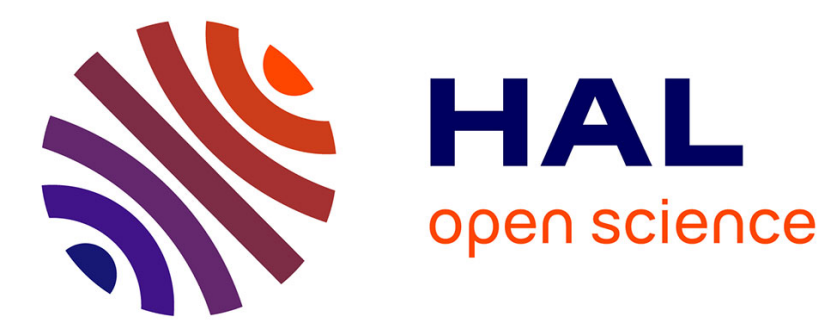

\title{
Induction Motors Bearing Failures Detection and Diagnosis: Park and Concordia Transform Approaches Comparative Study \\ Izzet Önel, Mohamed Benbouzid
}

\section{- To cite this version:}

Izzet Önel, Mohamed Benbouzid. Induction Motors Bearing Failures Detection and Diagnosis: Park and Concordia Transform Approaches Comparative Study. IEEE IEMDC'07, May 2007, Antalya, Turkey. pp.1073-1078. hal-00531271

\section{HAL Id: hal-00531271 \\ https://hal.science/hal-00531271}

Submitted on 2 Nov 2010

HAL is a multi-disciplinary open access archive for the deposit and dissemination of scientific research documents, whether they are published or not. The documents may come from teaching and research institutions in France or abroad, or from public or private research centers.
L'archive ouverte pluridisciplinaire HAL, est destinée au dépôt et à la diffusion de documents scientifiques de niveau recherche, publiés ou non, émanant des établissements d'enseignement et de recherche français ou étrangers, des laboratoires publics ou privés. 


\title{
Induction Motors Bearing Failures Detection and Diagnosis: Park and Concordia Transform Approaches Comparative Study
}

\author{
I.Y. Önel and M.E.H. Benbouzid, Senior Member, IEEE
}

\begin{abstract}
This paper deals with the problem of bearing failure detection and diagnosis in induction motors. Indeed, bearings deterioration is now the main cause of induction motor rotor failures. In this context, two fault detection and diagnosis techniques, namely the Park transform approach and the Concordia transform, are briefly presented and compared. Experimental tests, on a $0.75-\mathrm{kW}$ two-pole induction motor with artificial bearing damages, outline the above approaches main features for small and medium size induction motors bearing failure detection and/or diagnosis.
\end{abstract}

Index Terms-Induction motor, bearing failure, fault detection, diagnosis, Park transform, Concordia transform.

\section{INTRODUCTION}

Rotor failures now account for a larger percentage of total induction motor failures [1]. Bearings deterioration is now the main cause of rotor failures. The main factor of bearing faults is dust and corrosion. Induction motors are often operated in hard conditions. That is why foreign materials, water, acid and humidity are the main reasons of bearing deteriorations. Contamination and corrosion frequently accelerate bearing failures because of the harsh environments present in most industrial settings. Dirt and other foreign matter that is commonly present often contaminate the bearing lubrication. The abrasive nature of this minute particles, whose hardness can vary from relatively soft the diamond like, cause pitting and sanding actions that give way to measurable wear of the balls and raceways. Bearing corrosion is produced by the presence of water, acids, deteriorated lubrication and even perspiration from careless handling during installations. Once, the chemical reaction has advanced sufficiently, particles are worn off resulting in the same abrasive action produced by bearing contamination. Improper lubrication includes both under and over lubrication. In either case, the rolling elements are not allowed to rotate on the designed oil film causing increased levels of heating. The excessive heating causes the grease to break down, which reduces its ability to lubricate the bearing elements and accelerates the failure process [2].

I.Y. Önel is with the Electrical Engineering Department, ElectricalElectronics Faculty, Yildiz Technical University - YTU Merkez Kampus, Istanbul, Turkey (e-mail: senol@yildiz.edu.tr).

M.E.H. Benbouzid is with the Laboratoire d'Ingénierie Mécanique et Electrique (LIME), University of Western Brittany, Rue de Kergoat - BP 93169, 29231 Brest Cedex 3, France (phone: +33 2980180 07; fax: +332 980166 43; e-mail: m.benbouzid@ieee.org).
Bearing problems are also caused by improperly forcing the bearing onto the shaft or into the housing. This produces physical damage in the form of brinelling or false brinelling of the raceways, which leads to premature failure. Misalignment of the bearing, which occurs in the four ways depicted in Fig. 1, is also a common result of defective bearing installation. In a small fraction of induction motor applications, bearings prematurely fail due to electrical causes. Currents flowing through induction motor bearings have the potential of creating premature failure of these bearings. Figure 2 shows the typical fluting pattern in a bearing race due to metallurgical damage from interrupted electrical current flow. Increased noise and vibration are typical symptoms of bearing damage for a bearing such as this. Over time, lubrication fatigue and mechanical wear lead to ultimate bearing failure [3].

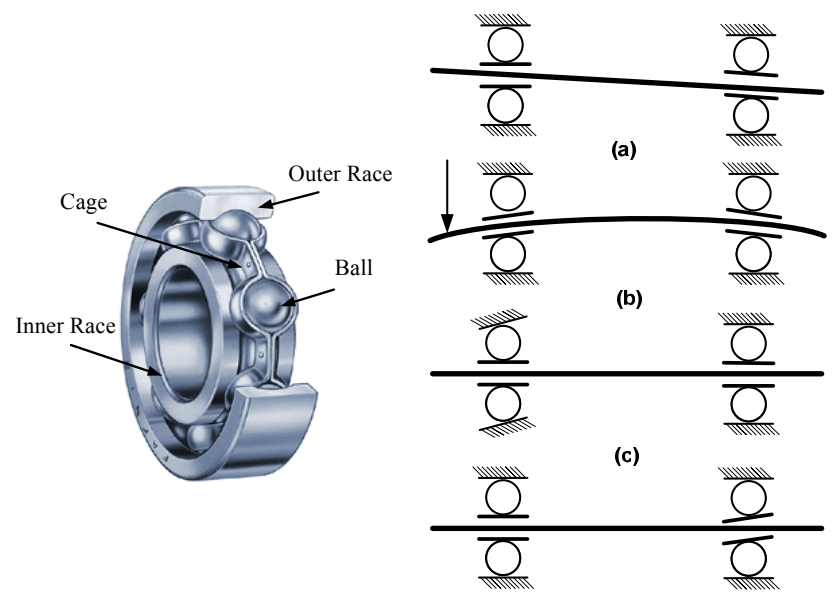

(d)

Fig. 1. (a) Misalignment (out-of-line), (b) Shaft deflection, (c) Cocked or tilted outer race, (d) Cocked or tilted inner race.

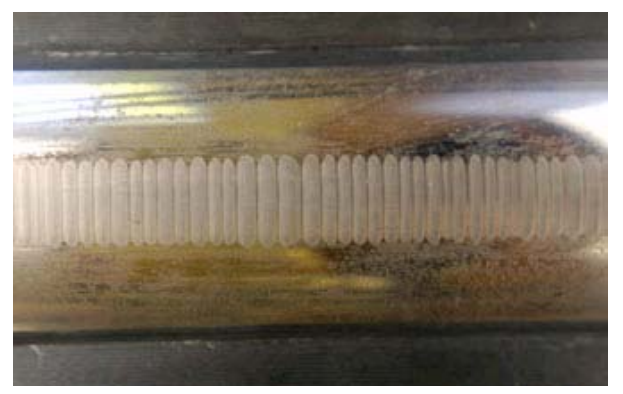

Fig. 2. Bearing fluting. 
There are many condition monitoring methods used for the detection and the diagnosis of bearing failure: vibration measurements, temperature measurement, shock pulse method and acoustic emission. Among these vibration measurements are most widely used. In fact, large induction motors are often equipped with mechanical sensors, which are primarily vibration sensors such as proximity probes. However, these are delicate and expensive. Moreover, it is not economically or physically feasible to provide the same for smaller induction motors.

Owing to the infeasibility of these traditional techniques because of the economical constraints in small and medium size induction motors, stator current harmonics measurement is appearing as an alternative to the vibration measurement methods. Indeed, various researchers have suggested that stator current monitoring can provide the same indications without requiring access to the motor. This technique utilizes results of spectral analysis of the stator current or supply current of an induction motor for the diagnosis [4].

In this context and when the available literature is scanned, it can be found fault detection and diagnosis techniques based on the induction motor stator current patterns processing. These techniques are based on Park transform or Concordia transform. The global applicability of the Park approach has been demonstrated in [5] for induction motor stator faults and in [6-7] for bearing failures. The Concordia approach has been also successfully applied for the detection and the diagnosis of stator faults in [8] and faults in a PWM inverter feeding an induction motor in [9].

This paper is then devoted to the comparison of the Park and the Concordia transforms as fault detection and diagnosis approaches in the particular case of bearing failures. Moreover, this comparison is very useful as Park and Concordia transforms are often mingled [8].

\section{PARK TRANSFORM VERSUS CONCORDIA TRANSFORM}

A two dimensional representation can be used for describing three-phase induction motor phenomena. A suitable one being based on the stator current Park vector. Park transform reduces the number of current components and makes the calculation easier.

In a three-phase induction motor, stator current has three $(a, b, c)$ components. When Concordia transform is applied to the mains, $s D$ and $s Q$ components of the stator current are obtained. This transform is governed by (1).

$$
\left\{\begin{array}{l}
I_{s D}=\sqrt{\frac{2}{3}} I_{a}-\frac{1}{\sqrt{6}} I_{b}-\frac{1}{\sqrt{6}} I_{c} \\
I_{s Q}=\frac{1}{\sqrt{2}} I_{b}-\frac{1}{\sqrt{2}} I_{c}
\end{array}\right.
$$

These components are stationary according to the stator.

If Park transform (2) is applied to the $s D-s Q$ system, $D$ and $Q$ components are obtained.
$\left[\begin{array}{l}I_{D} \\ I_{Q}\end{array}\right]=\left[\begin{array}{cc}\cos \theta_{r} & \sin \theta_{r} \\ -\sin \theta_{r} & \cos \theta_{r}\end{array}\right]\left[\begin{array}{c}I_{s D} \\ I_{S Q}\end{array}\right]$

These components are stationary according to the rotor. Figure 3 summarizes the above transforms where $I_{s}$ is the stator current vector that rotates at the angular frequency $\omega_{s}$.

Transforming $a b c$ system to $s D-s Q$ system is very simple. Park transform is more complicated than Concordia's. Indeed, rotor speed or position must be known. But stator current $D$ and $Q$ components have valuable information for bearing fault detection. Indeed, they contain the speed information that is obviously affected by bearings condition.

Using this new Park transform, the obtained $D$ and $Q$ current trajectory is not a circle, as it is the case for $s D$ and $s Q$ current trajectory: It is an ellipse as schematically depicted by Fig. 4. It is also a simple reference figure that allows the detection of abnormal conditions by monitoring the deviations of acquired patterns: The occurrence of a bearing failures manifest itself in the deformation of the ellipse in the case of Park transform and in the deformation of the circle in the case of Concordia transform. These are very simple reference figures that allow the detection of abnormal conditions by monitoring the deviations of acquired patterns.

In the following they will be applied for the detection and the diagnosis of bearing failures.

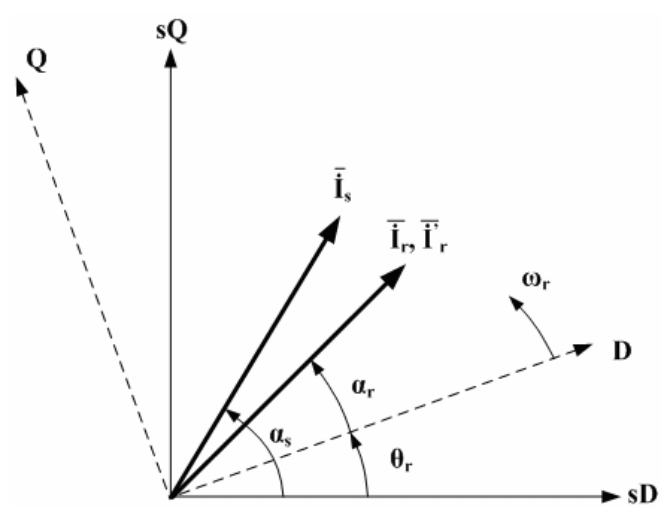

Fig. 3. Representation of $s D-s Q$ and $D-Q$ axes.

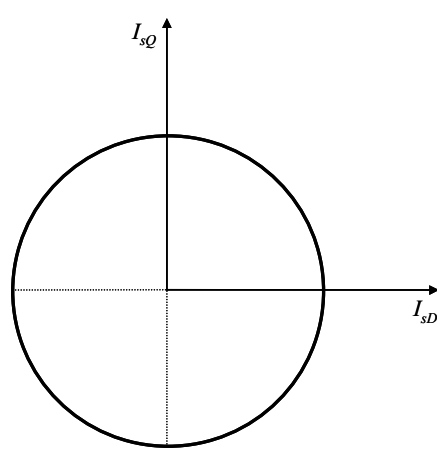

(a)

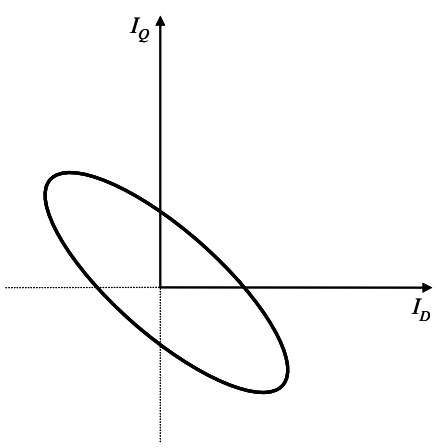

(b)
Fig. 4. Current patterns for ideal conditions: (a) Concordia transform. (b) The new Park transform. 


\section{EXPERIMENTAL RESULTS}

\section{A. Test Facility Description}

Figure 5a describes the experimental setup. It is composed of two parts: a mechanical part that has a tacho-generator, a three-phase squirrel cage induction motor and a car alternator. The tacho-generator is a DC machine that generates $90 \mathrm{~V}$ at $3000 \mathrm{rpm}$. It is used to measure the speed. It produces linear voltage between 2500 and $3000 \mathrm{rpm}$. The alternator is a threephase synchronous machine with a regulator and a rectifier circuit that stabilize the output voltage at 12 VDC. The advantage of using a car alternator instead of DC generator is obtaining constant output voltage at various speeds. The induction motor could be identically loaded at different speeds.

Moreover, if the induction motor is supplied from the network, motor current will have time and space harmonic components as well as bearing fault sourced harmonics. This makes it harder to determine the bearing failure effect on the stator current and therefore complicates the fault detection process. For these reasons, the induction is fed by an alternator. By this way, supply harmonics effects are eliminated and only bearing failure effects could be observed on the stator current. Figure $5 \mathrm{~b}$ is then given to illustrate the experimental test philosophy.

The tested induction motor has the following rated parameters: $0.75 \mathrm{~kW}, 220 / 380 \mathrm{~V}, 1.95 / 3.4 \mathrm{~A}, 2780 \mathrm{rpm}, 50$ $\mathrm{Hz}, 2$ poles, Y-connected. It has two 6204.2ZR type bearings.

From the bearing data sheet the following parameters are obtained: The outside diameter is $47 \mathrm{~mm}$ and inside one is 20 $\mathrm{mm}$. Assuming that the inner and the outer races have the same thickness gives the pitch diameter $D_{P}=31.85 \mathrm{~mm}$. The bearing has eight balls $(N=8)$ with an approximate diameter of $D_{B}=12 \mathrm{~mm}$ and a contact angle $\theta=0^{\circ}$. These bearings are made to fail by drilling holes of various radiuses with a diamond twist bit while controlling temperature by oil circulation in experiments. Some of the artificially deteriorated bearings are shown in Fig. 6.

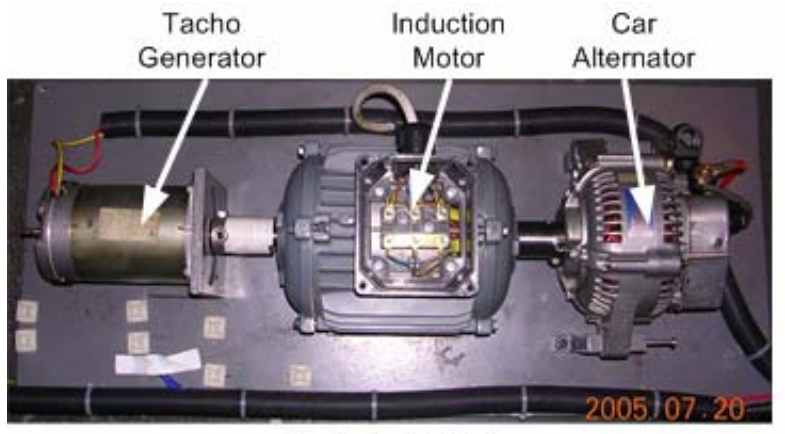

Mechanical Part of Experimental setup

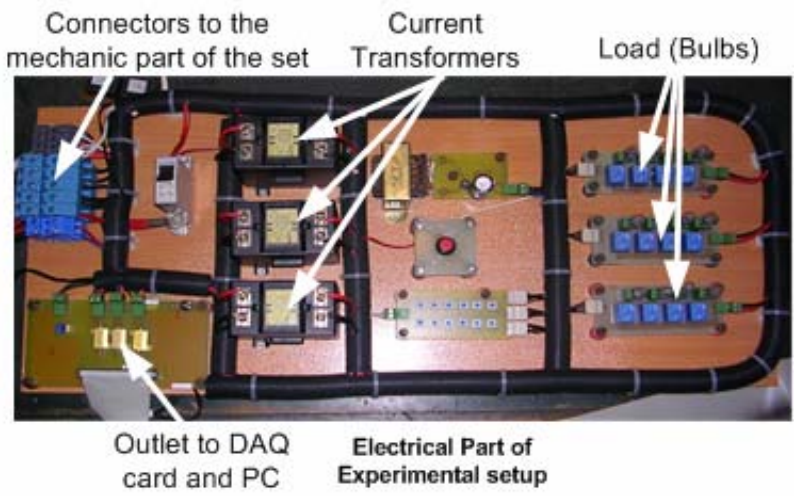

(a)

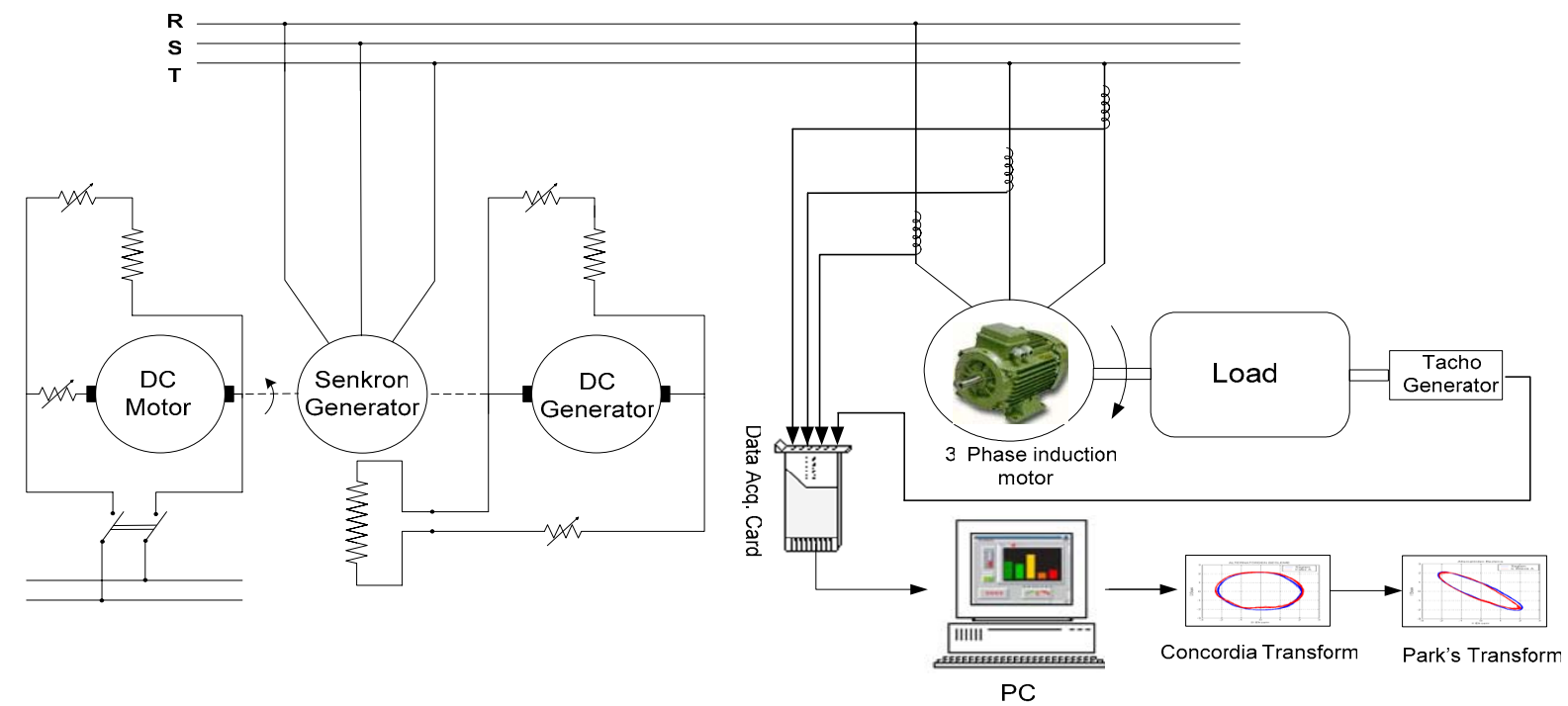

(b)

Fig. 5. Test facility. 


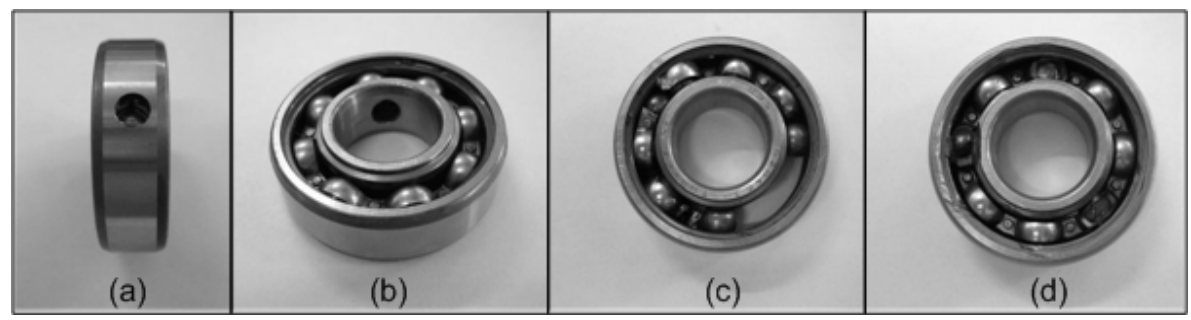

Fig. 6. Artificially deteriorated bearings: (a) outer race deterioration, (b) inner race deterioration, (c) cage deterioration, (d) ball deterioration.

\section{B. Concordia Transform Experimental Results}

Sampling frequency is chosen as $10 \mathrm{kHz}$. All the data obtained are used to compute stator $s D-s Q$ and $D-Q$ components to obtain $s D-s Q$ (Concordia) and $D-Q$ (Park) patterns. The induction motor has been initially tested with healthy bearings in order to determine the reference current Concordia and Park patterns. Afterwards, it has been tested with the different artificially deteriorated bearings.
These experiments are summarized by Fig. 7 in case of Concordia patterns and by Fig. 8 in case of Park Patterns.

It could be seen that bearing failures cause a clear deformation of the stator current $s D-s Q$ and $D-Q$ trajectories. Moreover, an insight analysis of Fig. 8 leads to an obvious classification of bearing failures according to a specific deformation of the initial ellipse: this clearly show the diagnosis capability of the Park transform approach.

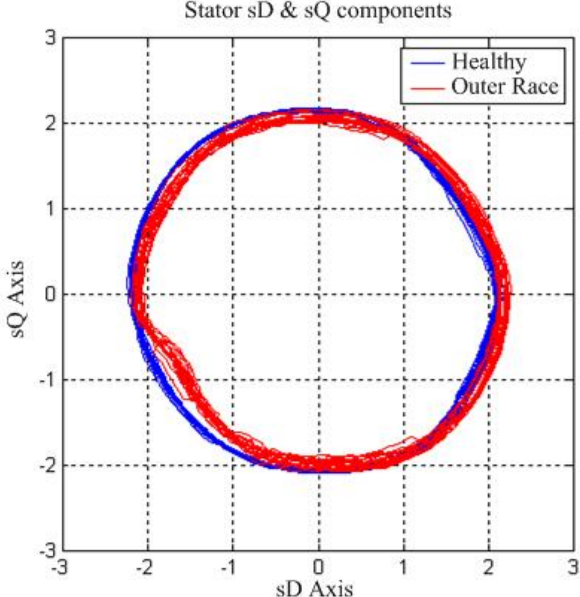

(a)

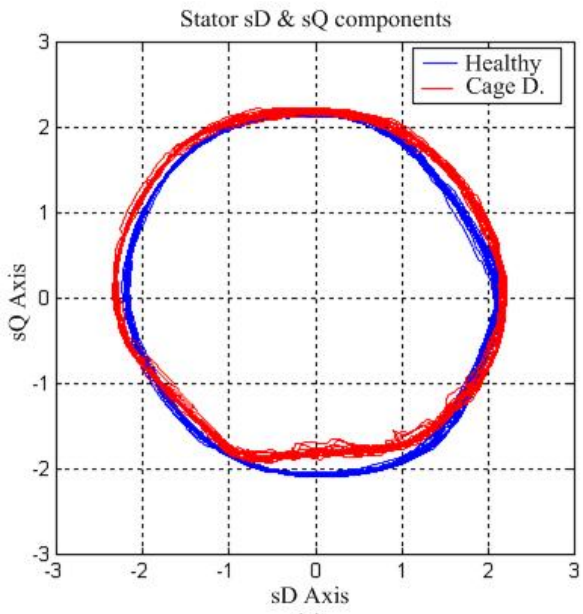

(c)

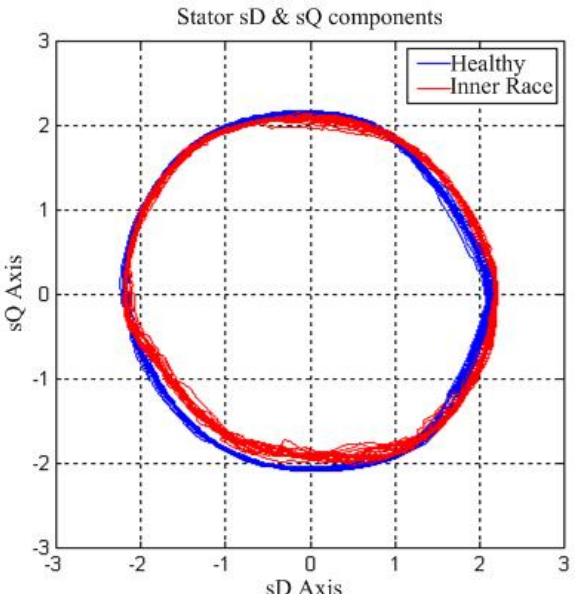

(b)

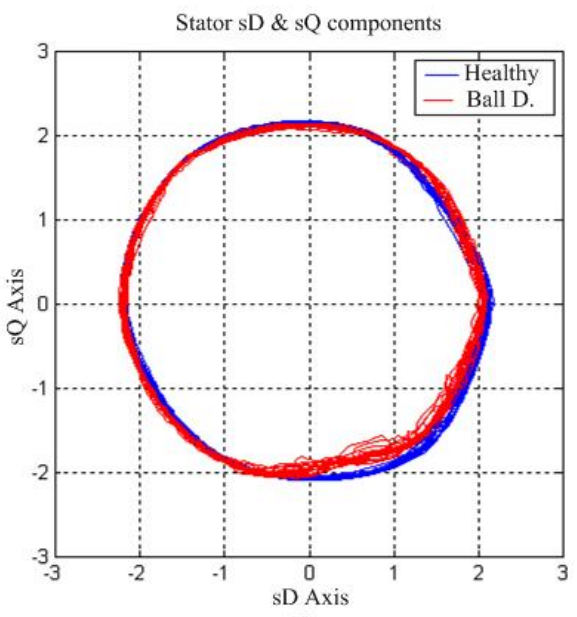

(d)

Fig. 6. Stator current $s D-s Q$ component trajectory comparison:

(a) Healthy and outer race defect, (b) Healthy and inner race defect, (c) Healthy and cage defect, (d) Healthy and ball defect. 


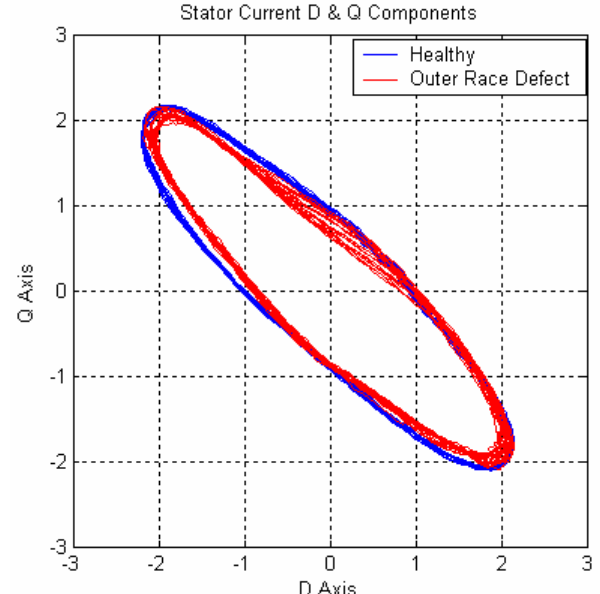

(a)

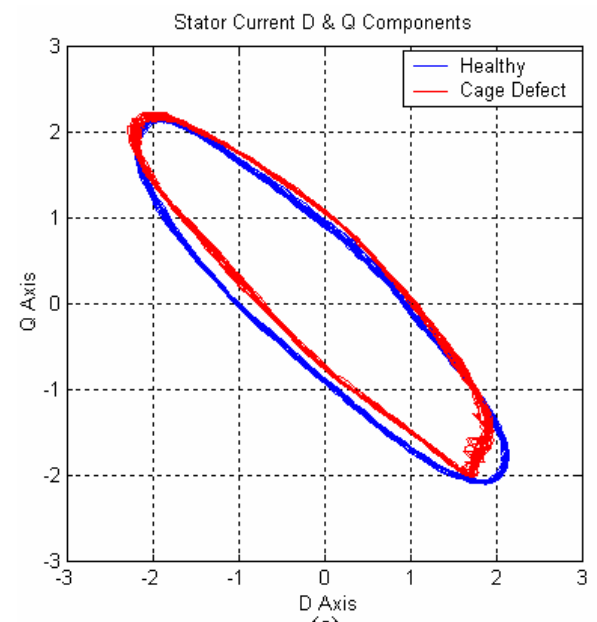

(c)

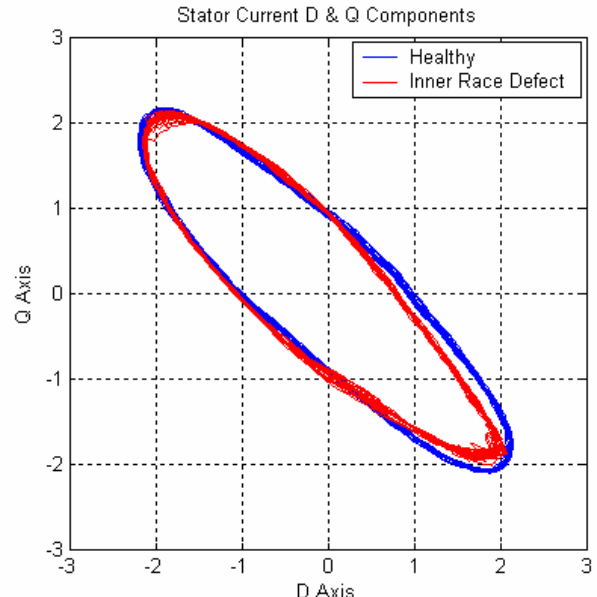

(b)

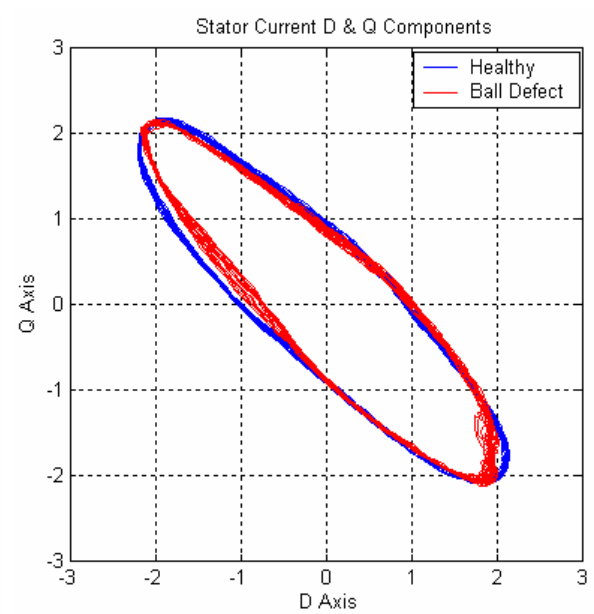

(d)

Fig. 7. Stator current $D-Q$ components trajectory comparison:

(a) Healthy and outer race defect, (b) Healthy and inner race defect, (c) Healthy and cage defect, (d) Healthy and ball defect.

The fault detection and diagnosis process could be summarized as: the occurrence of a bearing failures manifest itself in the deformation of the current pattern corresponding to a healthy condition (failure detection). The deformation analysis will lead to the failure diagnosis. Therefore, according to the above experimental analysis, it seems that the Park transform approach has better diagnosis capabilities then the Concordia transform. However, the Park approach is a speed sensor based one that is not the case of the Concordia approach. This drawback could be justified by the importance of bearing failures diagnosis as they account for approximately $50 \%$ of total failures in induction motors. Otherwise, sensorless fault detection and diagnosis should be performed as in [10], where the speed is estimated from the motor current rotor slot harmonic.

\section{FAult Detection AND Diagnosis Process Automation}

Park and Concordia transform approach should be associated with techniques that automate the process of bearing failure detection and diagnosis. For that purpose, two techniques are extensively used: neural networks [5-6], [9] and fuzzy logic [8], [11-12].
Neural networks are used due to their numerous advantages. Indeed, when properly tuned, they could improve the diagnosis performance. They are easy to extend and modify, and they could be easily adapted by the incorporation of new data as they became available. For the analysis of stator current Park vector patterns, neural networks may be used as classifying systems. To perform classification, it is necessary to attach to each pattern a label that describes the operational state of the induction motor at the time of collecting the pattern. The input to the network is a pattern and the output is the class label. For illustrations, Fig. 8 illustrates the fault detection and diagnosis global approach.

The main reason for choosing a fuzzy approach is the very nature of the changes in the attributes. It is nonlinear, and in addition, it would be unreasonable to expect that each time the same level of a particular fault arises, that the attributes would measure exactly the same values. The boundaries between two levels of a certain fault or between two faults are not sharply defined, and therefore the use of a classic true or false logic is inappropriate, whereas use of a fuzzy logic instead is highly justified. For illustrations, Fig. 9 illustrates the fault detection and diagnosis global approach. 


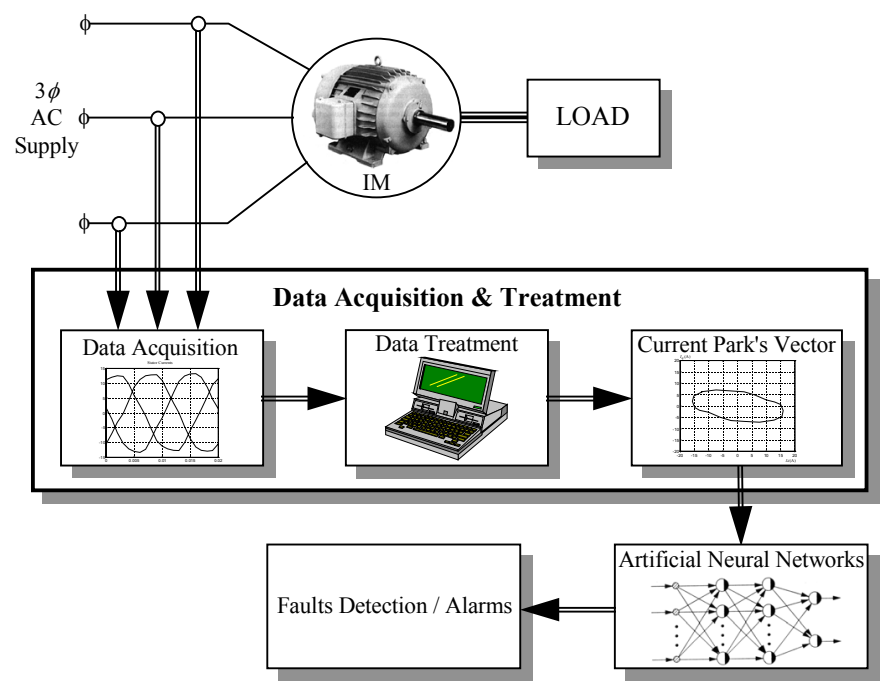

Fig. 8. Diagnosis process automation using neural networks [5].

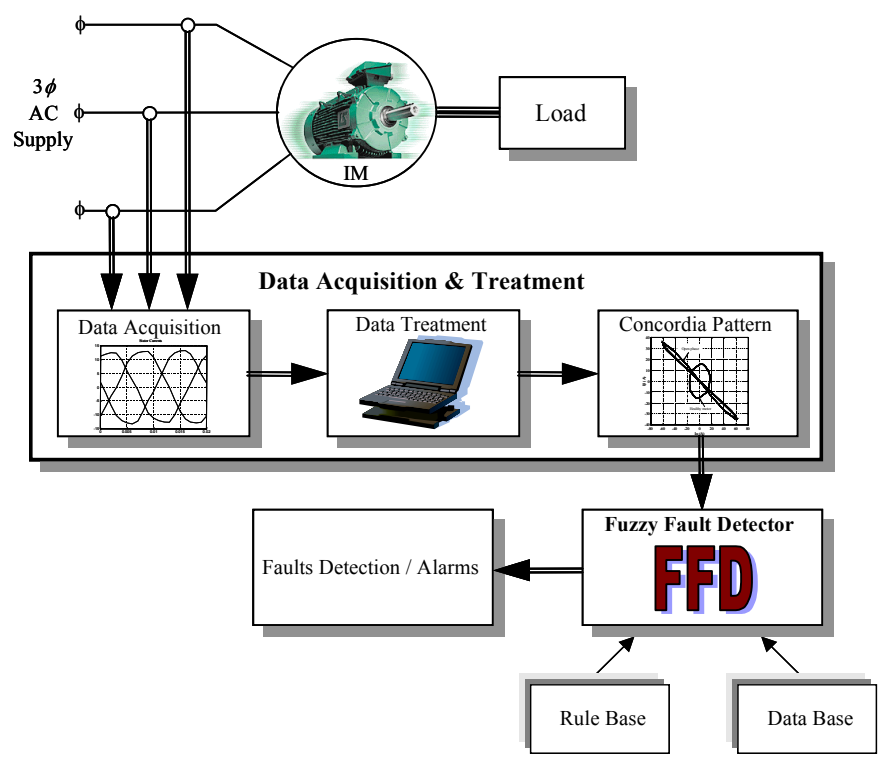

Fig. 9. Diagnosis process automation using fuzzy logic [8].

\section{CONCLUSION}

This paper dealt with the problem of bearing failure detection and diagnosis in induction motors. It compares two fault detection and diagnosis techniques, namely the Park transform approach and the Concordia transform. Experimental tests were carried out on a $0.75-\mathrm{kW}$ two-pole induction motor with artificial bearing damages.
These results seem to indicate that Park transform approach has better diagnosis capabilities then the Concordia transform. However, the Park approach is a speed sensor based one that is not the case of the Concordia approach. This drawback could be justified by the importance of bearing failures diagnosis as they account for approximately $50 \%$ of total failures in induction motors. Otherwise, sensorless fault detection and diagnosis should be performed using the Park transform approach as the speed could be estimated from the motor current rotor slot harmonic.

\section{REFERENCES}

[1] M.E.H. Benbouzid et al., "What stator current processing based technique to use for induction motor rotor faults diagnosis?," IEEE Trans. Energy Conversion, vol. 18, n², pp. 238-244, June 2003.

[2] T. Harris, Rolling Bearing Analysis. Wiley: New York, 2001.

[3] R.F. Schiferl et al., "Bearing current remediation options," IEEE Industry Applications Magazine, vol. 10, $\mathrm{n}^{\circ} 4$, pp.40-50, July-August 2004.

[4] M.E.H. Benbouzid, "A Review of induction motors signature analysis as a medium for faults detection," IEEE Trans. Industrial Electronics, vol. 47, n5, pp. 984-993, October 2000.

[5] M.E.H. Benbouzid et al., "Monitoring and diagnosis of induction motors electrical faults using a current Park's vector pattern learning approach," IEEE Trans. Industry Applications, vol. 36, n³, pp. 730735, May-June 2000.

[6] I.Y. Önel et al., "Induction motors bearing failures detection and diagnosis using a RBF ANN Park pattern based method," in Proceedings of ICEM'06, Chania, (Greece), 2006.

[7] J.L.H. Silva et al., "Bearing failures in three-phase induction motors by extended Park's vector approach" in Proceedings of the IEEE IECON'05, Raleigh, NC (USA), pp. 2591-2596, November 2005.

[8] M.E.H. Benbouzid et al., "Induction motor stator faults diagnosis by a current Concordia pattern based fuzzy decision system," IEEE Trans. Energy Conversion, vol. 18, n4, pp. 469-475, December 2003.

[9] D. Diallo et al., "Fault detection and diagnosis in an induction machine drive: A pattern recognition approach based on Concordia stator mean current vector," IEEE Trans. Energy Conversion, vol. 20, N³, pp. 512 519, September 2005.

[10] K. Kim et al., "Sensorless fault diagnosis of induction motors," IEEE Trans. Industrial Electronics, vol. 50, n5, pp. 1038-1051, October 2003.

[11] D. Diallo et al., "Fuzzy detection and diagnosis of fault modes in a voltage-fed PWM inverter induction motor drive," IEEE Trans. Industrial Electronics, 2007.

[12] M.Y. Chow, Methodologies of Using Neural Network and Fuzzy Logic Technologies for Motor Incipient Fault Detection, Singapore: World Scientific, 1997 